\title{
A Crise do Direito do Trabalho no Brasil
}

\author{
José Eduardo Campos de Oliveira Faria ${ }^{(*)}$
}

\begin{abstract}
«Onde estejam ausentes as características de estabilidade e de validade límitada - onde quer que as chamadas «leis» da história ou da natureza ( ) conservem uma «legalidade» que pode mudar de dia para dia $\epsilon$ que clama por validade para toda espécie humana - estaremos nos con. frontando com a ilegalidade, embora não com a anarquia, uma vez que a ordem pode ser mantida por meio de uma organizaçăo coerciva. O resultado evidente es a criminalização de todo o mecanismo de governo, como ja aprendemos dos governos autoritários».
\end{abstract}

Hannah Arendt, in Criwes da República

SUMARIO: 1 - INTRODUCAO. 2 - A CRISE DO DIREITO LIBERAL. 3 O DIREITO DO TRABALHO NUMA SOCIEDADE EM TRANSICAO. 4 - A ORDEM LEGAL EMERGENTE. 5 - CONCLUSAO.

\section{1 - INTRODUÇÃO}

«As coisas deste mundo estão num fluxo tão constante que nada permanece muito tempo no mesmo estado». Escrita por John Locke há mais de trezentos anos, esta afirmação hoje certamente poderia ser tomada como simples truismo. Mesmo assim, como reconheceu Hannah Arendt, uma importante pensadora liberal conservadora do século $\mathrm{XX}$, para quem a civilização somente foi possivel porque os homens souberam criar mecanismos institucionais capazes de canalizar, amoldar e estabilizar as mudanças sociais e econômicas, essas palavras continuam sendo importantes para se compreender o alcance de um dos grandes dilemas da atualidade: a questão do equilíbrio entre a estabilidade jurídico-política e as transformaçōes sócio-econômicas entre a normalidade da ordem legal e os riscos de anomia, entre os periodos de legitimidade e os momentos de crise - em síntese, entre a obediência e a desobediência.

«Obviamente, diz ela, nem a capacidade do homem para a mudança nem sua capacidade para a preservação são ilimitadas, sendo a primeira limitada pela extensão do passado no presente - nenhum homem começa $a b$ ovo - e a segunda pela imprevisibilidade do futuro. $\mathrm{O}$ anseio do homem por mudança e sua necessidade de estabili-

(*) Professor-adjunto do Departamento de Fllosolia e Teoria Geral do Direito da USP. 
dade sempre se equilibraram e controlaram mutuamente; e o nosso vocabulário corrente, que distingue duas facções, os progressistas e os conservadores, indica um estado de coisas no qual esta balança foi desregulada» $\left({ }^{1}\right)$.

Subjacente a essa afirmação encontram-se, na verdade, as questões básicas que, desde Max Weber, têm animado a ciência política e a filosofia do direito: por que os homens se submetem? Em que condições? Quais os meios externos em que se baseia a subordinação do homem pelo homem? Em que justificativas internas se fundamenta essa subordinação? Estas indagações abrem caminho, por sua vez, para diversas questões relativas à teoria do direito e à sociologia do direito. Em que medida as leis não pervertem a liberdade justamente a pretexto de protegê-las? Haverá normas realmente capazes de refletir uma opinião comum em contextos estigmatizados pelas contradições sociais, pelo relativismo do conhecimento e pelos antagonismos de classe? Em que medida a inevitabilidade dos conflitos não transforma o direito num simples instrumento de controle social, de tal forma que os códigos jamais deixarão de conter uma dimensão repressiva? Nesse caso, o equilíbrio entre a estabilidade e a mudança não será sempre um «ideal» romântico, possível do ponto de vista retórico e impossível na prática? O que garante a legitimidade de um equilíbrio temporário, historicamente localizado?

Hannah Arendt tinha plena consciência do alcance destas indagações. O direito não estava no centro de suas preocupações mas, na tradição de Kant, ela o via como uma técnica social destinada a induzir os homens a um determinado tipo de comportamento. Como essa técnica em princípio poderia ser empregada para a consecução de todo e qualquer fim, muitas de suas reflexões concentraram-se em torno dos problemas da violência, da autoridade, da legitimidade e da desobediência civil. Afinal, «todos nós vivemos e sobrevivemos por uma espécie de consentimento tácito que, no entanto, seria difícil chamar de voluntário. Como podemos exercer nossa vontade sobre o que já está determinado? Dissidência implica em consentimento e é a marca do governo livre; quem sabe que pode divergir sabe também que de certo modo está consentindo quando não diverge. O consentimento tácito não é ficção; é inerente à condição humana. Todavia, o consentimento a leis específicas ou políticas específicas, com as quais não se identifica mesmo que sejam resultado de decisões majoritárias» ${ }^{(2)}$.

A questão aqui proposta, evidentemente, é a da eficácia jurídica relacionada com a da legitimidade política. Mas esse é um problema ambíguo. Se não vejamos. De um lado, a eficácia muitas vezes é confundida com o simples «reconhecimento» das normas por uma sociedade homogeneamente considerada, postas por um Estado encarado

(1) Cf. Hannah Arendt, Da desobediência oivil, in Crises da República, Săo Paulo, Perspectiva, 1973, pp. 71-72.

(2) Idem, ibidem, p. 79 
como um aparelho neutro e isento. Nesse caso, a ralidez clas instituições do direito apareceria como sendo «a forma psicológico-social do objetivamente justo» $\left({ }^{3}\right)$. No entanto, a realidade contemporânea é complexa demais para que as normas reconhecidas pelo poder político do Estado também o sejam por toda comunhão social. De outro lado. a eficácia, enquanto condição da vigência de uma ordem jurídica, depende da efetividade do sistema político. Nesse sentido, uma norma qualquer não seria válida porque é eficaz; pelo contrário, seria válida apenas se a ordem política a que pertence no seu todo, for efetiva. Todavia, qual a natureza dessa efetividade? Em outras palavras: o que a legitima? Os liberais responderiam: a democracia representativa. Mas os criterios do liberalismo, contra-atacando, diriam que esse modelo de representação política encontra-se em crise.

Voltemos à Hannah Arendt: «freqüentemente se argumenta que o consentimento à Constituição, o consensus universalis, implica em consentimento às leis estatutárias também, pois no governo representativo o povo também ajudou a fazê-las. Tal consentimento... é completamente ficticio; de qualquer modo, nas cinscunstâncias atuais perdeu toda sua plausibilidade. O próprio governo representativo está em crise hoje; em parte porque perdeu, com o decorrer do tempo, todas as praxes que permitiam a real participação dos cidadãos, e em parte porque atualmente sofre gravemente da mesma doença que o sistema de partidos: burocratização e tendência do bipartidarismo em não representar ninguém exceto a máquina dos partidos». Em suma: «tanto há freqüentes ameaças à Constituição pela administração, com a conseqüente perda de confiança pública nos processos constitucionais, quer dizer, a retirada do consentimento, como também veio à tona mais ou menos ao mesmo tempo, a mais radical má vontade de certas camadas da população em reconhecer o consensus universalis» $\left.{ }^{4}\right)$.

Eis aí os limites de nossa discussão sobre a correlação entre a estabilidade jurídico-política e as transformações sócio-econômicas. O liberalismo forjou a concepção de Estado de Direito numa perspectiva altamente formalista e racional, deixando o máximo de liberdade possível ao mercado político e econômico para definir a substância da ordem jurídica. Esta seria apenas uma ordem coativa constituida à base de um sistema fechado, que se basta a si mesmo e que regulamenta o emprego da força nas relações sociais. A grande característica do direito é a possibilidade de regular sua própria criação e aplicação, uma vez que somente daquele sistema fechado é que se pode deduzir soluções para todos os casos determinado em que as normas devam ser aplicadas. Conseqüentemente, uma norma se torna válida se é criada de acordo com as prescrições das normas de grau superior; mas somente a autoridade competente pode verificar sua falta de validez - e

(3) Cf. Miguel Reale, Filosofia do Direito, São Paulo, Saraiva, 1962, pp. 513-515.

(4) Cf. Hannah Arendt, Da desobediência civil, op. cit., p. 79. 
essa autoridade, por sua vez, responde a uma vontade explicita cristalizada por um mandato legislativo.

O papel da leis assim concebidas é, portanto, bastante claro: seu objetivo precípuo é o de propiciar a segurança e o controle do sistema social. Ordenados e articulados segundo um príncipio de racionalidade sistêmica da qual se destaca a exigência de uma coerência lógico-formal, os códigos permitem desta maneira a estabilização das mudanças sociais num quadro de legalidade. Mas as mudanças em si, como diz Hannah Arendt, sempre foram o resultado de uma ação extra-legal. E a história contemporânea, a seu ver, está repleta de exemplos comprovando empiricamente como as grandes transformações das instituições de direito se deram em decorrência dos conflitos sócio-econômicos.

Um desses exemplos, de grande atualidade entre nós, é o da evolução da legislação trabalhista. Neste momento em que o direito do trabalho brasileiro vem sofrendo uma grande transformação em seus procedimentos formais e em seu conteúdo, em virtude da grande tensão hoje existente nas relações entre o capital e o trabalho, é importante identificar o sentido da discussão proposta por Hannah Arendt sobre o impacto das mudanças sociais sobre a ordem jurídica. «Toda substância da legislação trabalhista - o direito ao acordo salarial, o direito de se organizar e fazer greve - foi, disse ela, precedida por décadas de desobediência, às vezes violenta, às leis que no fim das contas se mostraram obsoletas» $\left(^{5}\right)$.

Retomemos, pois, essa discussão. Ela pode não ser de todo original, é certo, mas seguramente nos permitirá entender as razões da polêmica hoje travada em torno das tentativas de modernização de nosso direito do trabalho, tamanho o descompasso existente entre o modelo de desenvolvimento sócio-econômico em curso e suas formas jurídicas. O objetivo deste artigo, enquanto exercício analítico no âmbito da sociologia do direito, é menos o de examinar os aspectos formais da nova lei de greve e negociação coletiva e mais o de identificar o contexto em que sua introdução se situa.

\section{2 - A Crise do Direito Liberal}

Formuladas e organizadas a partir de um prisma ideológico específico, simbolizado pela concepção de Estado de Direito herdada do liberalismo oitocentista, instituições judiciárias sempre tiveram sua efetividade diretamente associada a uma visão pouco dinâmica das relações de produção e a uma percepção excessivamente individualizadora das clivagens e das tensões sociais. Daí o caráter peculiar tanto das leis quanto dos próprios procedimentos legais, estruturados com uma finalidade básica: generalizar, trivializar e atomizar os antago-

(5) Idem, ibidem, p. 73. 
nismos, para melhor reprimí-los, amortecendo e dispersando seus efeitos desagregadores sobre os padrões vigentes de sociabilidade e dominação.

A partir das crises estruturais do capitalismo industrial, porém, a ordem juridica liberal passa a enfrentar sérios problemas para manter-se intocada como um conjunto organicamente fechado e completo de normas, dotado de uma coerência interna lógico-formal e tendo no vértice de uma constituição a condição de validade de todo o sistema jurídico. Em virtude da expansão e do fortalecimento dos movimentos operários, cada vez mais eficazmente mobilizados na defesa de seus interesses materiais e políticos, os conflitos nas relações entre capital e trabalho coletivizam-se.

Para equacioná-los sem, no entanto, alterar os rígidos principios constitutivos e as diretrizes formais de seu sistema normativo, a ordem jurídica liberal terminou por adotar, no âmbito da legislação trabalhista, regras mais abertas e procedimentos mais flexíveis. É por isso que o Direito do Trabalho se desenvolve fora dos padrões legalistas de forte inspiração positivista, provocando assim uma gradativa desarticulação das coordenadas ideológicas de um modelo político-administrativo garantido por códigos fundados nos pressupostos máximos do individualișmo que permeou o movimento codificador do início do século XIX: os primados da livre-iniciativa, da autonomia da vontade, da inviabilidade da propriedade, etc.

Tal desarticulação cresce na mesma proporção em que decresce a capacidade de autocontrole da economia de mercado, produzindo grandes transformações no interior do direito público e privado. Esse fenômeno ocorre especialmente na passagem do século XIX para as primeiras décadas do século XX, período em que a substituição daquele individualismo pelas abordagens doutrinárias mais realistas agrupadas em torno do personalismo jurídico, uma corrente do pensamento jurídico que elegeu o «humanismo» como sua palavra de ordem, fundando-a na encíclica Rerum Novarum do papa Leão XIII, traduz a capacidade de respostas da burguesia às diversas e contraditórias pressões sociais.

Com a crise dos anos 30, essas transformações vão consolidando a transição dos papéis ortodoxos do Estado liberal, reduzido a um simples provedor de serviços básicos para as funçōes abrangentes de um Estado pretensamente «social», convertido em regulador, indutor, empresário e árbitro no âmbito de um capitalismo crescentemente monopolista. O que esse processo de expansão do intervencionismo estatal revela é como, diante da complexidade sócio-econômica emergente do colapso do capitalismo concorrencial, os grupos e classes dominantes criam e recriam novas e diferentes condições institucionais para a reprodução do capital, mediante articulações inéditas entre os setores público e privado. O direito privado sofre, então, um amplo processo de publicização. E o direito público, por sua vez, submete-se um processo paralelo de «administrativização», ou seja, reduzido às normas dispositivas do Direito Administrativo. 
Afinal, ao se tornarem mais sistemáticas, elevando tanto a regulamentação quanto a direção da economia a tarefas primordiais do Estado intervencionista, as ações governamentais provocaram tamanhas modificações paralelas nas técnicas legislativas e nos institutos jurídicos tradicionais que, na prática, terminaram por romper com o equilibrio então existente entre as normas ordinárias e as normas constitucionais. Efetuadas sob a justificativa de que «o direito estava em atraso com os fatos», motivo pelo qual «os fatos se revoltaram contra os códigos», ocasionando assim «a decadência do contrato» e até mesmo «inutilidade das leis», segundo as palavras de patéticos juristas conservadores desesperançados com o futuro do direito privado $\left(^{6}\right)$, tais modificações configuraram um Executivo cada vez mais ágil, flexível e absorvente, incapaz de ser fiscalizado pelos mecanismos legislativos e judiciários imaginados pelo liberalismo jurídico-político.

Todas essas transformações na estrutura do Estado capitalista expressam, em suma, combinações politicas e soluções legais pelas quais gradativamente foram conciliados os diferentes tipos e níveis de conflito. Quais são esses conflitos? De um lado, por exemplo, os próprios antagonismos de interesses das diversas frações da burguesia entre si, à medida que o desenvolvimento tecnológico e seu impacto sobre o rítmo de industrialização envolveram desigualmente os segmentos detentores do capital. De outro, as clivagens entre essas mesmas frações, enquanto classe, e a emergência de movimentos operários organizados na reivindicação de cidadania, mobilizando-se eficientemente na luta pela maximização do direito de participação, em termos de igualdade de oportunidades e de maior influência na formulação, implementação e execução das políticas públicas.

Esses conflitos se implicam e interagem na dinâmica do Estado capitalista, possibilitando assim a formação de inúmeras coalisões nas sempre renovadas tentativas dos legisladores de neutralizar tensões e absorver inseguranças de correntes dos conflitos de interesse entre as frações da burguesia no poder e os movimentos populares mais articulados (7). Do ponto de vista das instituições de direito, sua principal conseqüência é a explosão da rigidez hierárquica e do formalismo conceitual dos modelos fechados de uma ordem jurídica concebida como instrumento de controle social apenas para contextos estáveis. Isto porque, à medida que a crescente complexidade sócio-econômica exige do Estado respostas imediatas e de pronto efeito, esses padrões jurídicos são deslocados do plano Legislativo para o âmbito do Exe-

(6) Cl. P. Bonnet, Le droit en retard sur les faits, Paris, LGDJ, 1930; Gaston Marin, La revolte des faits contre le code, Paris, Bernard Grasset, 1927; Georges Ripert, Le déclin du droit, Paris, LGDJ, 1945, e René Savatier, Les métamorphoses économiques et sociales du Droit Privé d'aujourd'hui, Paris, Dalluz, 1959.

(7) Ver Claus Offe, The welfare State and future of socialism: an interview with Claus Offe, in TwLos, 1984, e Critêrios de racionalidade e problemas funcionais da acão política administrativa, in Problemas estruturais do Estado Capitalista, Rio de Janeiro, Tempo Braslleiro, 1984. 
cutivo. Por causa disso, as limitações legais à intervenção do Estado no domínio privativo são pragmaticamente pervertidas. Ou seja: na prática, vão-se revelando inócuas. $\mathrm{E}$, a um nível tal, que os cidadãos em busca da certeza na proteção de seus direitos acabam tendo de se guiar pela própria práxis decisória dos órgãos burocráticos do Executivo. Dito de outro modo: são obrigados a ver como tais organismos agem e decidem no cotidiano da administração pública para, em seguida, aprendendo a respeitar expectativas modificadas pelas inúmeras decisões possiveis, e aceitando-as como um fato, saber o que se pode esperar do Executivo, ou dele exigir.

Tal processo é bastante perceptível a partir da expansão das respostas normativas crescentemente generalizadas e abrangentes ao desafio da regulação e da administração das relações entre capital e trabalho na dinâmica do desenvolvimento capitalista, cuja conseqüência concreta foi o rompimento, em termos operacionais, da própria divisão de competência e objetos expressa pela dualidade direito público $\times d i$ reito privado. Com a conversão do valor econômico no traço distintivo do direito contemporâneo, tal a preocupação da burguesia com a maximização do lucro e tal a mobilização do operariado pela ampliação de suas conquistas sociais, surgiram então instituições jurídicas novas que não se enquadram em nenhum dos ramos tradicionais do ordenamento normativo liberal. Não tem sido por acaso que, muitas vezes, essas instituições são convertidas mais em focos de incertezas e confrontação do que em fonte de segurança e balizamento de expectativas.

\section{3 - O Direito do Trabalho Numa Sociedade em Transição}

O Direito do Trabalho é, nesse sentido, um dos exemplos mais significativos de uma regulamentação crescentemente política e pragmática de uma economia que, pelo caráter pouco uniforme e linear do desenvolvimento capitalista, deixou de ser o produto aleatório do livre jogo das forças de mercado ${ }^{(8)}$. Sua expansão, como disse antes, vem ocorrendo fora da legalidade estrita forjada pelo liberalismo jurídico-político. Mas, precisamente, a legislação trabalhista sempre se desenvolveu como uma consciente e crescente afronta a essa legalidade. Tanto que, nas economias industrializadas da Inglaterra e da França, ao final do século XIX e começo do século XX, a greve foi considerada crime de insurreição antes de ser admitida como um direito positivo, do mesmo modo como a formação de centrais sindicais de há muito já havia sido incorporada à práxis do operariado, antes de ser reconhecida e oficializada pela chancela parlamentar».

Em suma: à medida que a sobrevivência de uma negação jurídica foi deixando de bastar para dissimular a formação de um direito novo, a função social deflagradora da inovação legislativa acabou sendo

(8) Cf. Jean Cruet, A vida do direito e a inutilidade das leis, Salvador, Progresso, 1956. 
desempenhada por delinqüientes. Isto mesmo: criminosos e insurgentes - ao menos do ponto de vista dos Códigos em vigor. Afinal, ao transformar a proibição legal de realização de greve e de associação sindical em direitos efetivamente conquistados a partir da confrontação política contra as instituições então vigentes, foi a vanguarda do operariado que constituiu, ao preço de impasses e repressões, uma nova ordem jurídica a partir de delitos generalizados.

Embora no Brasil o advento da Consolidação das Leis do Trabalho esteja formalmente associado ao corporativismo dos anos 40, quando o Estado Novo procurou antecipar-se às pressões operárias mediante a cooptação de algumas de suas lideranças, a história do Direito do Trabalho nos países avançados ajuda a entender o alcance dos movimentos sindicais nacionais, especialmente os do ABC, num momento peculiar da história do país: um periodo em que, enquanto se aguarda a realização da Constituinte, muitas vezes superestimando seu potencial transformador e reformador, ainda se é obrigado a viver sob a tutela de uma ordem jurídica carente de credibilidade e de legitimidade. Mas uma ordem vigente que formalmente continua constituindo as relações sociais - e que, como tal, tem sido invocada por certos setores oficiais para exigir do governo maior firmeza diante das múltiplas greves, formando assim um explosivo círculo vicioso entre a ameaça de repressão pura e simples, por um lado, e a ameaça de paralisação do país numa atitude típica de desobediência civil, por outro.

Talvez seja por isso que exista hoje uma grande simetria entre os delinqüentes-legisladores europeus e as vanguardas sindicais, representadas pelos metalúrgicos do ABC. A exemplo daqueles, estes também emergiram no bojo de um processo de industrialização que provocou significativas transformações qualitativas nas estruturas sócio-econômicas. Como decorrência dessas transformações, surgiu um sindicalismo novo e moderno, muito mais imune ao peleguismo e bem mais engajado politicamente do que o sindicalismo populista dos anos 60 . Organizadas de maneira eficiente, as lideranças emergente do $\mathrm{ABC}$ souberam encaminhar, mediante formas não-ortodoxas de pressão, como ocupação das empresas e controle sobre os equipamentos centrais, uma gama extremamente diferenciada de interesses e reivindicações - dos reajustes semestrais e trimestrais à comissões de fábrica, da estabilidade no emprego à redução da jornada de trabalho, da exigência de salário-desemprego à efetiva cobrança dos ganhos de produtividade.

Essas demandas configuram uma multiplicidade de situações inéditas. Mas nenhuma delas, evidentemente, apareceu de uma hora para outra. Tudo ocorreu aos poucos, num ritmo regular e crescente, à medida que o movimento dos metalúrgicos do $\mathrm{ABC}$ foi ampliando sua hegemonia sobre outras categorias sindicais, valendo-se de sua capacidade de pressão para obter da Justiça do Trabalho e do próprio governo sentenças e providências favoráveis aos seus interesses, e combatendo tanto o Executivo quanto o Judiciário à medida que suas 
reivindicações deixaram de ser atendidas, mediante um crescente desafio às leis. Dada a necessidade de reproduzir as condiçōes institucionais para a sua própria estabilidade e segurança, e face ao imperativo de contornar essas pressões sem tocar na integridade de toda a ordem jurídica, o regime pós-64 verticalizou seus organismos burocráticos e expandiu seu poder de intervenção nas relaçôes de produção para captar, articular, interpretar e reagir a pressōes contraditórias: de um lado, as do empresariado, invariavelmente criticando a estatização, porém defendendo soluções de força nos impasses trabalhistas; de outro, as do operariado, transformando reivindicações de benefícios materiais em instrumento de luta política.

$\mathrm{O}$ que as greves do $\mathrm{ABC}$ nos revelam, portanto, è que a Nova República nasceu sob o estigma de uma enorme contradição. Ela busca sua legitimidade, como se sabe, em dois valores. O primeiro valor é de caráter negativo: a recusa ao passado autoritário, quando nem mesmo toda capacidade de repressão do regime pós-64 o habilitou a exigir o cumprimento da lei nas relações entre capital e trabalho. O segundo valor é de natureza positiva: a tentativa de estabelecer um regime de feições nitidamente liberais, uma vez que o ideal republicano maximiza a liberdade individual, impõe o equilíbrio entre os poderes e neutraliza o intervencionismo estatal. Mas em que medida, como indagava Oliveira Vianna ao desprezar com argumentos sólidos os principais ideológicos da primeira Constituição da República, a 1891, é possível um Estado liberal para uma sociedade socialmente tão diferenciada e contraditória como a brasileira? Em que medida, podemos agora perguntar, será viável o retorno a um regime jurídico na melhor tradição do liberalismo oitocentista em meio a um contexto sócio-econômico cuja crescente complexidade já não mais comporta soluções judiciais individualizantes, especialmente nos setores mais modernos e dinâmicos da economia nacional?

As críticas ao idealismo republicano feitas por Oliveira Vianna, ele próprio um dos ideólogos da CLT, são surpreendentemente atuais: «... os homens de elite intelectual do Brasil, não só os que possuem preparação jurídica, como os que possuem preparação literária e científica - os chamados homens de pensamento (doutrinadores, propagandistas, idealistas, publicistas, etc.) - podem ser enquadrados, mui legitimamente, dentro da categoria dos «homens marginais»... Porque. . . vivem todos eles entre duas culturas. Uma - a cultura do povo, que lhes forma o sub-consciente coletivo; outra a européia ou norte-americana, que lhes dá as idéias, as diretrizes de pensamentos, os paradigmas constitucionais, os critérios do julgamento político» $\left({ }^{9}\right)$. Convencido de que o princípio da autoridade deveria ter precedência quanto ao princípio da liberdade, e defensor da tese de que não existe condiçōes para um sistema político liberal sem uma sociedade liberal, a estratégia sugerida por este ideólogo da CLT também se revela, ele

(9) Cr. Oliveira Vianna, Instituições Políticas Brasileiras, Rio de Janeiro, 1949, p.p. 15-16. 
próprio, tão problemático, ineficaz e ilegítimo quanto o idealismo republicano por ele duramente criticado.

\section{$4-A$ Ordem Legal Emergente}

Eis, pois, no âmbito das relações entre capital e trabalho, os pólos de confrontação neste período pré-constituinte: de um lado, os marginais-liberais; de outro, os delinqüientes-legisladores. Estes termos podem ser retoricamente sonoros, é certo e o espectro de forças políticas entre ambos os pólos seguramente se destaca pela complexidade dos interesses em confronto e pela nuance das coalisões. Mas o conflito é real. Isto porque, os grupos operários emergentes das contradições do regime pós-64, foram capazes de romper o jogo da conciliação e da regulação corporativista na proporção direta da descoberta de seu poder de luta e barganha. À medida que esse poder de pressão e confronto tendeu a crescer em função de sua capacidade de articulação em setores estratégicos da estrutura produtiva do país, de sua própria localização num segmento industrial moderno, de sua disciplina tática e da força de sua própria estrutura burocrática interna, o fato é que os impasses deixaram de ser absorvidos pelos mecanismos judiciais e arbitrados de maneira eficiente pelos canais de representação partidária. Não apenas porque a vanguarda do movimento sindical recusa-se a praticar um jogo cujas regras ela considera como sendo de natureza «burguesa», mas, igualmente, porque os líderes do antigo $\mathrm{MDB}$, que se revelaram solidários com os grevistas do $\mathrm{ABC}$ em 1978, encontraram-se hoje no exercício do poder, em Brasília, praticando. . o discurso da ordem, denunciando infiltrações radicais e pregando o cumprimento da lei.

Não se pode subestimar esses fatos e essas contradições para se compreender os dilemas da Nova República. Afinal, a ordem jurídica cujo respeito agora é exigido por alguns de seus artífices foi, justamente, o principal objeto da crítica que os permitiu mobilizar a opinião pública para ascender ao Planalto. E a política econômica vigente não é qualitativamente diferenciada daquela cuja denúncia também serviu como fator de mobilização popular nos comícios da Aliança Democrática. Daí a dificuldade dos novos dirigentes em administrar pressões opostas e inconciliáveis. Uma, no sentido do resgate da liberdade de participação política em todos os níveis; no sentido da recusa deliberada de certos movimentos populares em exercer liberdade apenas nos limites de uma ordem legal desmoralizada até mesmo pelo próprio compromisso do governo com a causa da Constituinte ${ }^{10}$ ). Por que submeter-se a leis que, de tão ilegitimas, em breve serão alteradas? Por que não aproveitar este momento de transição para ampliar a ocupação do espaço político com a finalidade de negociar com maior peso o novo ordenamento jurídico?

(10) Esta discussão encontra-se mais aprofundada em José Eduardo Faria, A criso constitucional e a restauracão da legitimidade, Porto Alegre, Sérgio Fabris Editor, 1985. 
Estas indagações traduzem um processo de politização aparentemente irreversível nas relações entre capital e trabalho. Como o desenvolvimento capitalista dos anos 60 e 70 acarretou a diversificação das estruturas produtivas, a diferenciação das oportunidades de remuneração e a desigualdade das pressões trabalhistas sobre o empresariado, as categorias profissionais mais modernas tornaram-se gradativamente imunes às regulamentações e aos controles estatais. Eles puderam, assim, transcender a defesa de reindivindicações materiais imediatas. Ou seja: desqualificaram a estratégia governamental de negociar a manutenção da ordem por meio tanto de uma estratégia de distribuição primária de renda, pelo aumento dos salários, quanto de uma estratégia de distribuição secundária ou indireta de renda, mediante benefícios nos setores previdenciário e habitacional. $O$ que caracteriza a atuação dessas categorias, desde que se tornaram vanguarda do movimento sindical, é justamente seu esforço em rejeitar as compensações meramente econômicas como instrumento de negociação.

Estes fatos tornaram-se visiveis a partir do momento em que o choque do petróleo liquidou com o «milagre brasileiro», ao final do Governo Médici e início do Governo Geisel. Desde então, o Estado vem enfrentando crescentes dificuldades em conciliar sua função econômica, voltada ao processo acumulativo das empresas estatais e privadas, com sua função legitimadora, voltada à manutenção das tensões sociais numa situação de latência controlada. Isto porque a concessão de benefícios sociais, como forma de neutralização dos conflitos entre o operariado e o patronato, não produziu a lealdade desejada pelo regime pelo contrário, cada benefício concedido foi convertido em ponto de referência para novas reivindicações dos sindicatos, secundados pelas pressões paralelas das associações comunitárias e das comissões de justiça e paz. Ao mesmo tempo, o alto custo dessa estratégia também passou a exigir sucessivos aumentos na carga tributária, diminuindo os excedentes do empresariado e os levando, em suas campanhas antiestatizantes, a defender a concentração dos recursos públicos não em novas despesas sociais, porém em investimentos de infra-estrutura básica.

Ao denunciar a tendência de crescimento das despesas públicas numa velocidade maior do que a dos meios de financiá-las, o empresariado revelou então dupla percepção: de um lado, a consciência de que a manutenção dessa estratégia vinha estimulando o descomensurado crescimento do setor estatal, à medida que a elevação dos impostos para o atendimento das despesas sociais poderia abrir caminho para a monopolização da economia por parte das empresas públicas; de outro, a consciência de que a expansão do setor monopolista se fazia acompanhar de desemprego, pobreza e estagnação nos investimentos privados, exigindo assim do Estado maior apropriação dos excedentes para compensar os efeitos disfuncionais de sua crescente intervenção no domínio econômico.

O que esse círculo vicioso acarretou foi, como se sabe, o gradativo esgotamento do modelo autoritário pós-64. Como a questão da 
acumulação e da retomada do crescimento $\mathrm{x}$ produção do consenso $\mathrm{e}$ da «paz social» sempre ocorre num esquema eminentemente político, isso sobrecarrega demasiadamente o Estado. Ora, à medida que as pressões aumentam e os conflitos se tornam mais complexos, ampliam-se as prestações desordenadas de serviços públicos e as superposições de projetos. No limite, pois, as funções econômica e legitimadora do Estado tornam-se inconciliáveis, constituindo um processo altamente irracional do ponto de vista da coerência administrativa, da estabilidade tributária e da acumulação potencialmente lucrativa do capital privado.

Tanto as vanguardas sindicais quanto as lideranças empresariais estão conscientes, hoje, do dilema estrutural expresso por essa «crise fiscal» legada pelo regime pós-64 à Nova República. E esta, por sua vez, certamente em virtude de sua ambigüidade ideológica e da heterogeneidade de forças políticas em que se sustenta, parece indecisa diante da multiplicação das greves em todo o país. Daí o deslocamento do confronto entre patrões e empregados para o âmbito do próprio ministério Tancredo/Sarney. De um lado, os setores governamentais com nítidos compromissos com as entidades patronais de São Paulo estão a exigir duas medidas: num primeiro momento, a imposição pura e simples da lei, mediante o reconhecimnto formal das greves e a consequiente declaração de sua ilegalidade pela Justiça do Trabalho; e, num segundo momento, a ratificação da Convenção 87 da Organização Internacional do Trabalho, por parte do Congresso, que institucionaliza o pluralismo sindical ao autorizar, numa mesma base geo-espacial, a criação de organizações livres e concorrentes entre si. Tal convenção permite, pois, a formação de grupos antagônicos aos sindicatos já existentes, no plano das empresas, dificultando, no plano político, a ação de centrais sindicais. De outro lado, os setores governamentais cujos interesses partidários transcendem aqueles compromissos com o empresariado paulista estão a advogar uma intervenção estatal apenas supletiva e moderadora nos movimentos grevistas, uma vez que desejam aliviar a administração pública de uma sobrecarga contraditória de pressões, expectativas e responsabilidades. Como tem afirmado o ministro do Trabalho, que não é empresário, mas advogado licenciado do Sindicato dos Metalúrgicos de São Bernardo do Campo e um profundo conhecedor de suas reações, «fazer o que fazia seus antecessores, reconhecendo hoje o estado de greve, equivaleria a permitir que as empresas começassem as demissões indiscriminadas, o que ocasionaria respostas por parte dos grevistas e impediria soluções capazes de contornar o ambiente social e político».

\section{$5-$ Conclusões}

Ambas as alternativas oferecem riscos para a Nova República. A primeira delas certamente irá gerar uma onda repressiva que certamente liquidará com o discurso conciliatório e domesticador «neo-republicano». Mesmo porque, subjacente a toda repressão generalizada sempre está a intolerância, a intransigência e o radicalismo - o que 
pode abrir caminho para uma polarização capaz de pôr em xeque não apenas a própria Constituinte, mas o próprio processo de democratização do país. Já a segunda alternativa acena para uma reprivatização controlada dos riscos empregatícios, mediante uma estratégia de desestatização de certas funções governamentais e de relaxamento dos controles legais sobre os movimentos sindicais.

Tal solução revela a tendência desse setor governamental a levar - Estado, mediante uma reformulação estrutural da legislação trabalhista, a desfazer-se de certas pressões e reivindicações, transferindo-as de vez para os setores empresariais. Estes surpreendidos com a supressão da repressão governamental no caso das greves duradouras e com ocupação de fábricas, justamente quando vinham pressionando o atual governo a reduzir a participação do setor público na economia, vêem-se diante de um dilema: o de ou aceitar negociações diretas, e aí assumindo riscos de ter de fazer concessões inimaginadas quando decidiram apoiar e empolgar a Aliança Democrática, ou o de voltar-se novamente para o confortável regaço do Estado, abandonando o discurso antiestatizante em troca da proteção policial.

O que revela como, numa economia onde o empresariado tornou-se dependente dos créditos, subsídios e compras oficiais, a sobrevivência do privatismo paradoxalmente só pode ser assegurada, negociada, organizada e dirigida de forma política mediante arranjos corporativistas no âmbito dos órgãos burocráticos do Executivo.

Neste momento em que o confronto entre capital e trabalho corroi até mesmo a unidade governamental e compromete o novo regime, que perspectiva esse quadro de contradições e paradoxos acima descrito nos oferece? Qualquer resposta a esta indagação será, inevitavelmente, um simples exercício de futurologia. Mas é preciso ficar claro que as instituições jurídico-políticas, do modo como se encontram organizadas, já não estão mais à altura da complexidade sócio-econômica do país. De nada adianta pregar-se o cumprimento de uma legislação anacrônica e ilegítima nem praticar-se um discurso idealista e ingênuo quando a vanguarda trabalhista está firmemente convencida de que pode inviabilizar, com seu poder de mobilização popular e de inter. rupção de atividades produtivas e de serviços públicos, a política econômica do novo governo, obrigando-o assim a ter de optar por um quadro alternativo: ou efetuar amplas e tensas negociaçōes, sob o risco de uma paralisia decisória do país, ou optar por estratégias de violência repressiva. 